\title{
BOND CONNECTIONS OF HIGH PERFORMANCE CONCRETE (HPC) AND STEEL: "EXPERIMENTAL VERIFICATION OF SELECTION GLUED FOR TWO DIFFERENT SURFACES OF STEEL"
}

\author{
TOMÁš BlažeK ${ }^{a, b, *}$, JAKUB ŘEPKA ${ }^{a, b}$, TOMÁŠ Vlach ${ }^{a, b}$ \\ ${ }^{a}$ Czech Technical University in Prague, Faculty of Civil Engineering, Thakurova 7, 166 29 Prague 6, Czech \\ Republic \\ ${ }^{b}$ Czech Technical University in Prague, UCEEB, Trinecka 1024, 27343 Bustehrad, Czech Republic \\ * corresponding author: tomas.blazek@fsv.cvut.cz
}

\begin{abstract}
This article deals with the test of selected adhesives for glued connection of high performance concrete and steel plates with various surface treatments. Results of this experiment can be used as a basis for the possible anchoring of concrete facade elements to the steel grate, the possible bonding of steel anchors on the surface of concrete facade elements. High performance concrete is a concrete that exceeds the compressive strength $100 \mathrm{MPa}$ after 28 days. The second adherent is the uncoated steel and the steel with zinc coating as a second variant. Samples were tested in two different ways. The first experiment verified the single tensile strength of bond connection. The second test verified the shear strength, which is very important for connection designing.
\end{abstract}

KEYWORDS: HPC, concrete, steel, joint, connection, glue, epoxy resin.

\section{INTRODUCTION}

High performance concrete (HPC) has been increasingly used already also in the Czech Republic both in structural such as bridges and other structures such as indoor and outdoor furniture or facade elements. Research at the Department of Building Structures, Faulty of Civil Engineering CTU in Prague is much focused on the development of lightweight concrete facade elements [1, 2]. Due to the corrosion of traditional steel reinforcement is more and more used alternative reinforcement in facade elements such as non-steel fibres, impregnated and non-impregnated technical textiles [3, 4]. It leads to the next lightening of elements hand in hand with development of HPC [5, 6. Their anchoring to the building structure is an essential part of the research. Due to their lower weight less anchorage capacity is required and it is getting interested also the bonding in addition to the traditional mechanical anchors [7, 8].

The existing facade elements are usually anchored using mechanical anchors of various shapes with different mechanisms and systems for rectification. These mechanisms can be visible or hidden and sometimes affect the view on the building envelope. Testing the mechanical anchors of the circumferential envelopes is addressed in more detail for example in ETAG 034 [9.

The aim of this work was selection of suitable adhesives commonly available on the market and their experimental verification on the connection of two basic materials. It was a high performance concrete (HPC) element representing for example facade element and steel plate representing steel grate. Both materials HPC and steel have almost zero porosity and minimal water absorption. These are more demanding conditions for bonding.

Adhesives are usually tested for one-stage stress test - blunt joint according to the CSN EN 15870 [10] standard and they are also usually tested for shear stress according to the CSN EN 1994-1-1 [1] standard. The shear test is not exactly according to the standard. Dimensions for presented experiment were approximately adapted to the dimensions of the facade elements and to the possibilities of the laboratory testing equipment. Finally four adhesives were tested on two selected commonly used types of steel adhesion finishes, black steel without any surface treatment and heat-galvanized adherent [12].

\section{MATERIALS USED FOR EXPERIMENT}

HPC developed at the Faulty of Civil Engineering CTU in Prague (FCE CTU) from local sources of raw materials has been already used for many applications and experiments. The same HPC has been also used for presented experiments in this paper. Mix design of used fine-grain self-compacting HPC is presented in Table 1. Water cement ratio was 0.25 and water binder ratio was only 0.20 . Compressive strength of used $\mathrm{HPC}$ was $113 \mathrm{MPa}$ on cubes with edge length 100 mm according to CSN EN 12 390-3 standard. Flexural strength (three point bending test) is $13.2 \mathrm{MPa}$ on prisms $40 \times 40 \times 160 \mathrm{~mm}$ according to CSN EN 101511 standard. In the past on the same mixture also direct uniaxial tensile strength has been tested and it is $6.7 \mathrm{MPa}$ on dog-bones with cross sectional area $30 \times 30 \mathrm{~mm}$ according to CSN 731318 standard and static modulus of elasticity in compression is $49.3 \mathrm{GPa}$ 


\begin{tabular}{lc}
\hline Mix content & $\mathrm{kg} / \mathrm{m}^{3}$ \\
\hline Cement I 42.5R (Č.m. cement, Mokrá) & 680 \\
Technical silica sand & 960 \\
Silica flour (ground quartz) & 325 \\
Silica fume (microsilica) & 175 \\
Superplasticizers & 29 \\
Water & 171 \\
\hline Total & 2,340 \\
\hline
\end{tabular}

TABle 1. HPC mix design.

on prisms $100 \times 100 \times 400 \mathrm{~mm}$ according to CSN ISO 6784 standard.

Two often used types of steel adhesion finishes were selected, black steel without any surface treatment and heat-galvanized adherent. The steel type was S235. In the experiment, four selected typical adhesives commonly available on the market were tested: Mamut Crystal Glue, Merbenit SF50, M3 and Sika Floor 156 - epoxy resin. The joint was experimentally subjected to tensile and shear stress and the mechanical behaviour of the adhesives was monitored. Measured values were the crosshead displacement of testing machine, force and time of loading process.

\section{EXPERIMENTS}

The basic HPC specimen dimensions for the tensile test were selected on the $100 \times 25 \times 25 \mathrm{~mm}$. The HPC adherent part was glued to the steel part with a dimension of $50 \times 25 \times 25 \mathrm{~mm}$. Logically the fully glued cross sectional area was $25 \times 25 \mathrm{~mm}$. All selected types of glues were applied on this whole area to achieve the ideal source just after 28 days of HPC hardening from the concreting. Described tensile test design and view on the real specimen in testing machine is presented in Fig. 1. Specimens after one week maturing were tested for the uniaxial tensile test with the calculated time until the failure $60 \mathrm{~s} \pm 20 \mathrm{~s}$. The displacement load speed was calculated on the $0.5 \mathrm{~mm} / \mathrm{min}$ and it was used for all tensile specimens.

The HPC adherent for the shear test were designed on $100 \times 60 \times 40 \mathrm{~mm}$. Dimensions of both steel adherents were similar $100 \times 60 \mathrm{~mm}$ with different thickness $20 \mathrm{~mm}$. The glued area in contact zone was $60 \times 50 \mathrm{~mm}$, but the specimens for shear test had two glued area because of required testing symmetry. It eliminated other undesirable stresses in the glued area. Described shear test design and view on specimen in testing machine after the testing procedure is presented in Fig. 2. The displacement load speed was calculated on the $0.2 \mathrm{~mm} / \mathrm{min}$ and also in the shear test was same for all groups of specimens.

\section{Results of the tensile test}

The goal of this tensile test was the determination of maximal tensile stress until failure of the adhesive complex consisting of HPC adherence, steel adherence and adhesive. The stress values were calculated using critical maximum breaking force and the bonded area approximately $25 \times 25 \mathrm{~mm}$. The tensile stress dependence on the displacement of testing machine crosshead is presented in Fig. 3 for all adhesives and also for both selected surface treatments of the metal adherence.

Presented curves are the average curves of three specimens for all selected types. The stress development was almost linear until the maximum value was reached. The description of stress development can be divided into three similar typical areas for all tested specimens.

The first is the area before the linear trend of curves. This part was nonlinear due to the gradual activation and pre-stressing of all elements in testing machine. The second area is with linear trend of stress increasing on the cross-beam until the moment of maximal force was reached. Different slope of curves suggests different stiffness of adhesives. It does not have to be the rule, but with higher adhesives stiffness also higher strengths have been achieved. Epoxy resin Sika Floor 156 achieved the best results, the damage point was in the HPC part. Commonly used construction adhesives in praxis on other chemical bases compared to the epoxy resin exhibited worse tensile properties. The third area is the part of curves behind the point of maximal force. For adhesives extruded from the tube (constructions or mounting adhesives), which has let's say a rubbery soft character, this part shows considerable ductility. And it is a negative option of epoxy resin, high values of tensile stress, but fragile material behaviour. Epoxy resin in general exhibits a sudden rupture, after the point of maximal force the epoxy resin is not able to transfer any load as visible in Fig. 3.

\section{Results OF THE SHEAR TEST}

In this part of the experiment the aim was to determine the maximum shear force and calculate the maximum shear stress before the failure of specimens. The shear stress was calculated based on the measured maximum force before the breaking point and the bonded two surfaces of the joint with cross sectional area approximately $60 \times 50 \mathrm{~mm}$.

The dependence of the stress on the displacement is presented in Fig. 4 in the form of graph, taking into account the surface treatment of the metal adherence similarly like in the case of previous described tensile test. Presented curves are also the average curves of three specimens for all selected types.

The description of stress development can be divided into three similar typical areas for all tested specimens similarly with previous described tensile test. Also the mechanical behavior of the joint is very similar. Epoxy resin reached the highest shear strength, but its behavior is fragile. In the moment when the maximum force in the contact area is reached, the 

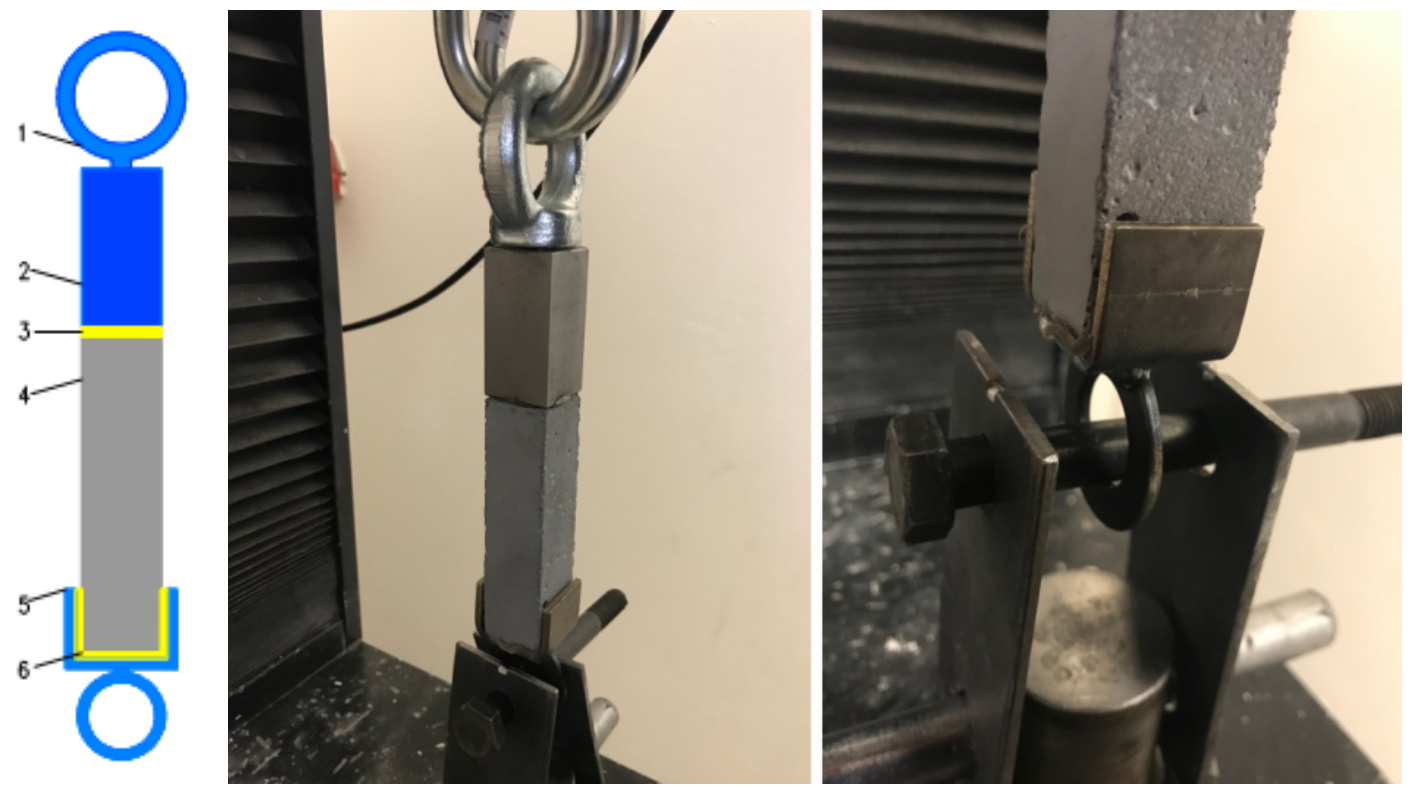

Figure 1. Design of tensile test: 1. Steel sleeve, 2. Steel adherent, 3. Selective glue, 4. HPC adherent, 5. Steel sleeve, 6. Construction glue. View on the real specimen in testing machine.
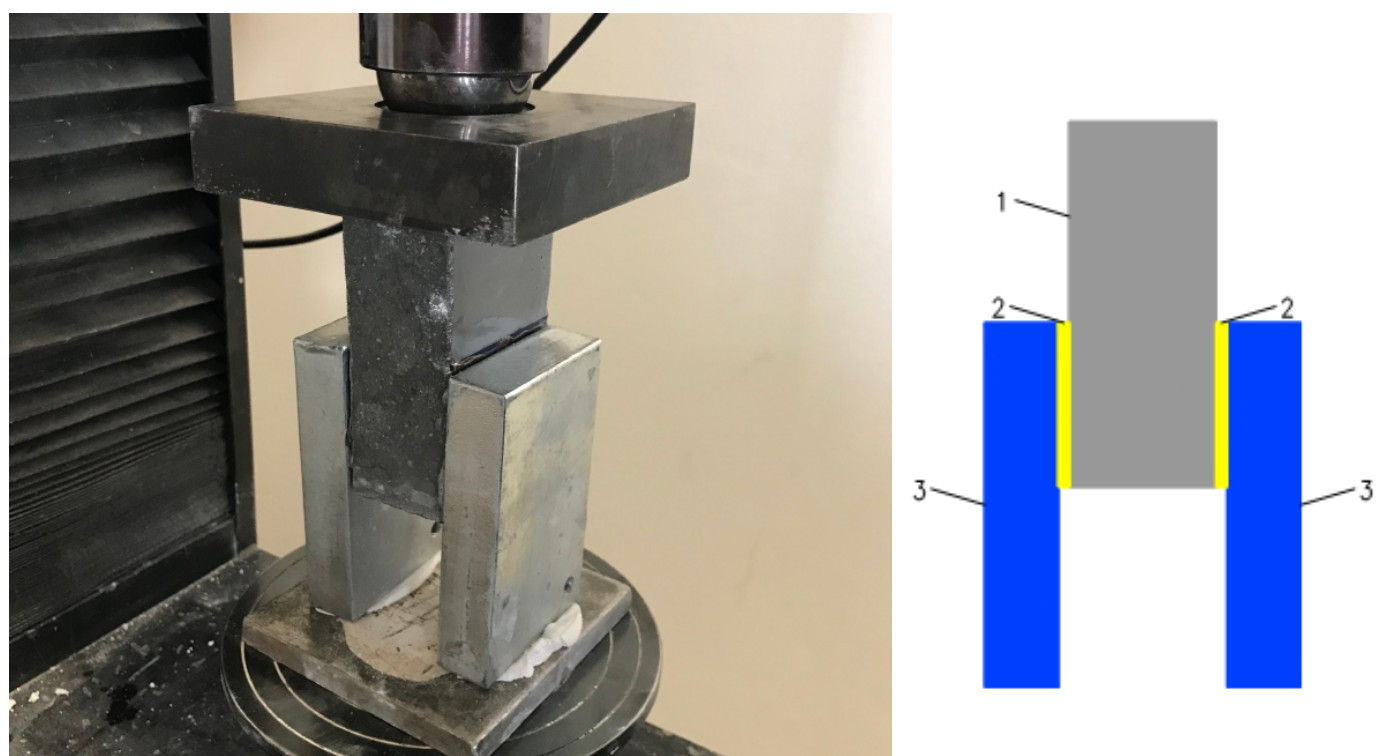

Figure 2. Results of the tensile test.

joint is unable to transfer any load. In contrast, other softer adhesives have a distinct plastic part of deformation and their behavior is more ductile. However, the shear strength is lower compared to the epoxy resin Sika Floor 156. Metal adherent without any surface treatment achieves better results compared to the metal adherent with zinc surface treatment. Only in the case of Merb glue opposite result were achieved. May be the surface of non-treated steel parts was incorrectly cleaned by technical gasoline or the surface was dusty or wet also in comparison with results of the tensile test.

The amount of resin in connected part and the method of resin application could have a significant effect on the results. Epoxy resin Sika Floor 156 and epoxy resins in general are two-component adhesives, where curing occurs when the both components are mixed together in the correct ratio. But in the cases of other adhesives (variants in tubes Merb, 3M and Mamut resin) reaction occurs with the access of air to the adhesive. Therefore, manufacturers recommend that the glue in tubes should be applied in the caterpillars side by side. This procedure provide access of air along the caterpillars and good process of hardening. This procedure was followed, but it was very difficult in praxis estimate how the caterpillars should be apart form others.

On several samples, the caterpillars were joined together along the length of the glued surfaces and adequate access of air was not ensured. For a shear test with a $50 \times 60 \mathrm{~mm}$ of glued surfaces, the area was so large that the adhesive was not well hardened in 


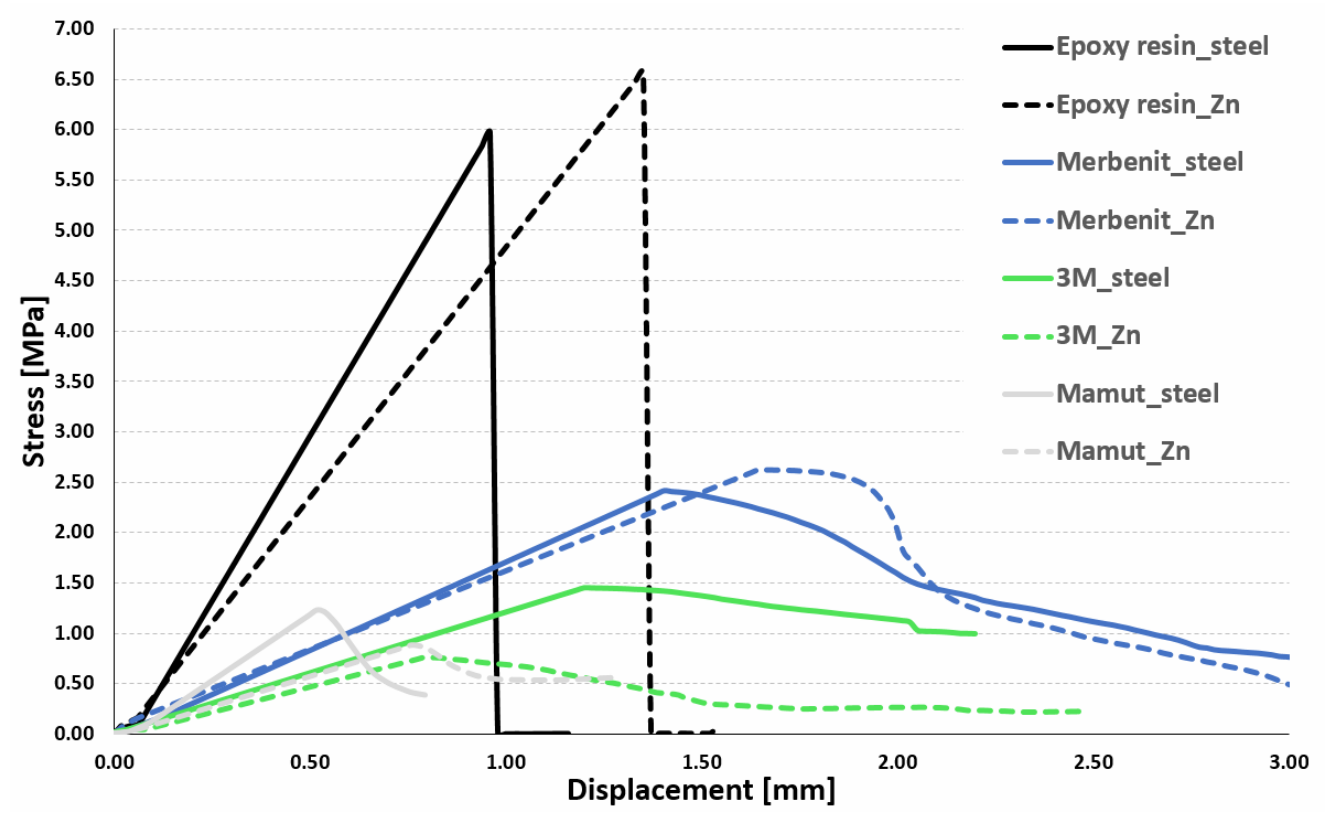

Figure 3. Addiction stress - displacement, tensile stress.

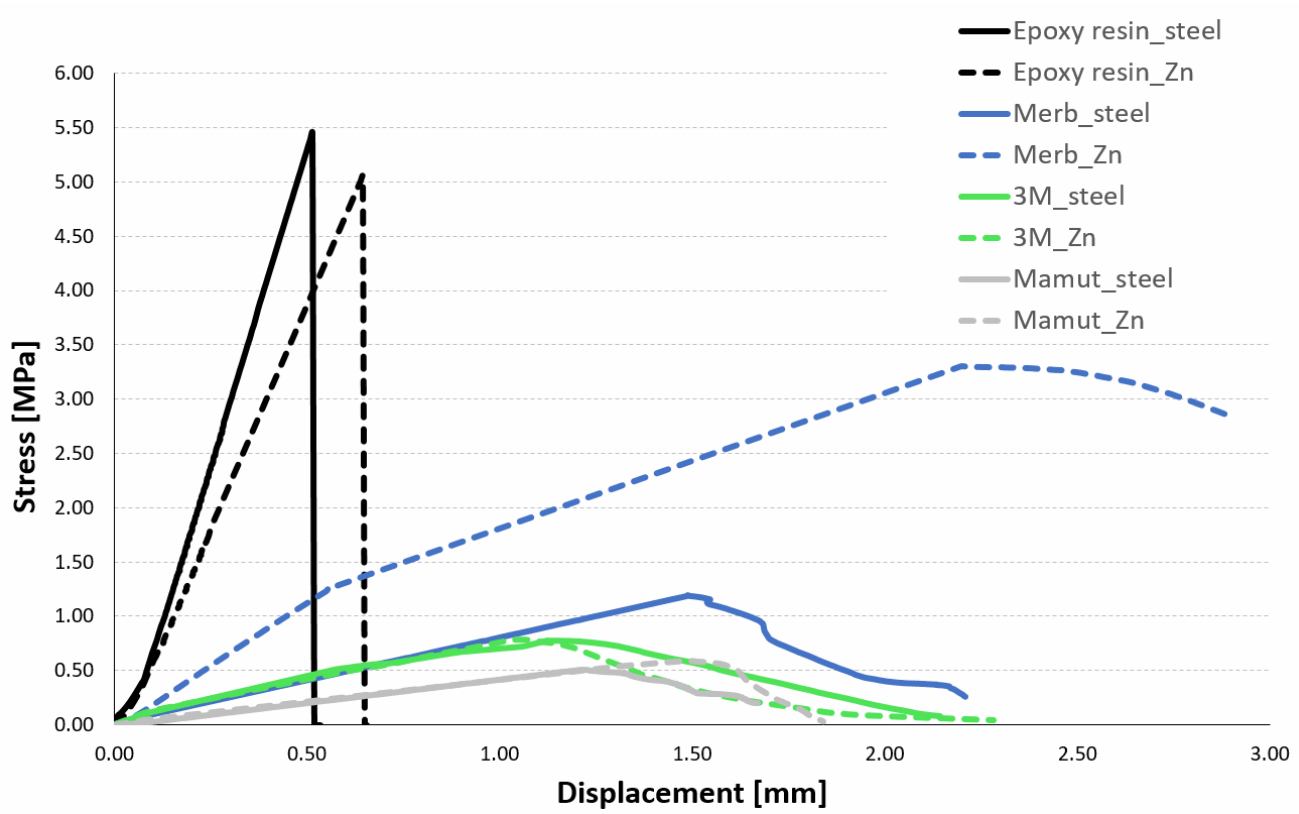

Figure 4. Addiction stress - displacement, shear stress.

the middle of the sample in these cases. Also use of HPC, which is waterproof, vapor-proof and airtight and does not allow access to air, is also of no effect.

\section{Conclusion}

The results of the tensile and shear tests correspond to each other. The best results with respect to strength values was achieved with epoxy two component resin Sika Floor 156. Type of failure was for all samples was lost of adhesion on the side of HPC adherence. All other selected adhesives with soft rubber character (Mamut, Merbenit and M3) had a cohesive failure. It means that after the moment when the maximal force in the contact area was reached, the joint was able to transfer load with lower values of tensile stress.

Two selected commonly used types of steel adhesion finishes, black steel without any surface treatment and heat-galvanized, reached similar results. Metal adherent without any surface treatment achieves may be little bit better average results compared to the metal adherent with zinc surface treatment. Only in the case of Merb glue opposite result were achieved because the surface of non-treated steel parts was incorrectly cleaned and prepared before the adhesive application.

Especially for soft rubber glues of lower strength (Mamut, M3) the treatment of steel adherence is extremely important before adhesives are applied. The 
manufacturer's technical sheet must be always strictly observed. Black steel is naturally characterized by a local occurrence of oxidized iron (scorch) which adversely affects the overall strength of the joint. The method of failure for presented adhesives was more or less cohesive with the visible small residues of oxidized iron.

\section{Summary}

The aim of this work was to verify the joining possibility of high performance concrete and steel adherence plates using adhesives. Four commonly available selected adhesives were experimentally tested. The glued joint was verified in the tensile and shear strengths according to the relevant standards. The results show that the highest values were achieved using an epoxy resin based adhesive for both performed testing methods. The observation also showed a negative effect of the oxidized iron at the surface on the shear strength of the complex. Tension strength is not fundamentally affected by this fact. This thesis does not solve the durability of used connection and its fire resistance, these propertieswill be verified in follow-up research.

\section{ACKNOWLEDGEMENTS}

This outcome has been achieved with the financial support of the TA CR 11124311 3111702A124 Subtle Concrete Furniture and Small Structures for the Railways Stations and also has been supported by Student Grant Competition, SGS18/108/OHK1/2T/11 - Environmental aspects of high performance cement composites and concrete with recycled aggregate including their durability and service life. The authors would like to acknowledge with gratitude all the financial help that was provided in order to support this original research.

\section{REFERENCES}

[1] T. Bittner, P. Bouška, M. Kostelecká, et al. Experimental investigation of mechanical properties of textile glass reinforcement. Applied Mechanics $\& 5$ Materials 732, 2014.

[2] A. Chira, A. Kumar, T. Vlach, et al. Textile-reinforced concrete facade panels with rigid foam core prisms. Journal of Sandwich Structures 86 Materials 2(18):200-214, 2016.

[3] L. Laiblova, T. Vlach, A. Chira, et al. Technical textiles as an innovative material for reinforcing of elements from high performance concretes (hpc). Advanced Materials Research 1054, 2014.

[4] L. Laiblová, T. Vlach, Ženíšek M. Využití technických textilií jako alternativní výztuže do subtilních fasádních panelů z vysokohodnotného betonu. Sympozium Společnosti pro techniku prostředí pp. 155-160, 2015.

[5] P. Reiterman, M. Jogl, V. Baumelt, et al. Development and mix design of hpc and uhpfrc. Advanced Materials Research 982, 2014.

[6] P. Reiterman, O. Holcapek, M. Jogl, et al. Long-term resistance of hpc to action of deicing salts. AIP Conference Proceedings p. 090007, 2014.

[7] ETAG 001. Guideline for european technical approval of metal anchors for use in concrete, 2000.

[8] P. Bernardin. Spojování kompozitních materiálů s kovem, 2016. Disertační práce, ZČU v Plzni.

[9] ETAG 034. Guideline for european technical approval of kits for external wall claddings, 2012.

[10] ČSN EN 15 870. Adhesives - determination of tensile strength of butt joints, 2009.

[11] ČSN EN 1994-1-1. Eurocode 4: Design of composite steel and concrete structures - part 1-1: General rules and rules for buildings, 2006.

[12] M. Bajer, J. Barnat. The glue-concrete interface of bonded anchors. Construction and building materials 34:267-274, 2012. 